\title{
Surgery for early stage small cell lung cancer
}

In this database study from the USA, survival following surgical treatment for stage I and II small cell lung cancer (SCLC) was investigated. The Surveillance, Epidemiology and End Results (SEER) database, sponsored by the National Cancer Institute, covers almost one third of the US population and captures $98 \%$ of all cancer cases in the surveyed areas. All patients between 1988 and 2007 with stage I or II SCLC were retrieved from the SEER database together with information regarding demographics, stage of disease, radiotherapy, resection as the treatment and survival. If available, pathological staging was used, otherwise patients were staged clinically.

Three thousand five hundred and sixty six patients were included, and 25\% underwent surgery, primarily lobectomy. The unadjusted median survival in the surgical group was 34 months compared with 16 months in patients who did not undergo surgery. The multivariable adjusted Cox regression model showed that patients with stage I or II SCLC who underwent surgery had better survival compared with patients who did not have surgery (HR $0.45,95 \%$ CI 0.39 to 0.51 ). This survival advantage was persistent in a number of subgroup analyses.

Limitations recognised by the authors were lack of information regarding concurrent diseases and chemotherapy. Consequently it cannot be ruled out that patients who were recommended surgery were healthier than the patients in the non-surgical group, and it is also possible that chemotherapy was more common in patients who underwent surgery, which may have influenced the prognosis.

Keeping these weaknesses in mind, this study is nevertheless a valuable addition to the growing literature providing evidence for a survival benefit from surgical treatment in stage I or II SCLC.

- Weksler B, Nason KS, Shende M, et al. Surgical resection should be considered for stage I and II small cell carcinoma of the lung. Ann Thorac Surg 2012;94:889-93.

\section{Ulrik Sartipy}

Correspondence to Dr Ulrik Sartipy, Department of Cardiothoracic Surgery and Anesthesiology, Karolinska University Hospital, Stockholm SE-171 76, Sweden; Ulrik.Sartipy@karolinska.se

\section{Competing interests None.}

Provenance and peer review Not commissioned; externally peer reviewed.

To cite Sartipy U. Thorax 2013;68:954.

Published Online First 27 October 2013

Thorax 2013;68:954. doi:10.1136/thoraxjnl-2012-202850 